\title{
Effect of betamethasone on airway obstruction and bronchial response to salbutamol in prednisolone resistant asthma
}

\author{
B GRANDORDY, N BELMATOUG, A MORELLE, D DE LAUTURE, J MARSAC
}

From the Service de Pneumologie, Hôpital Cochin, Paris

ABSTRACT Twelve patients with chronic severe asthma, having previously shown an $\mathrm{FEV}_{1}$ increase of less than $20 \%$ of the predicted value with prednisolone treatment (20-60 mg daily for 10 days), took part in a double blind crossover comparison of equipotent anti-inflammatory doses of betamethasone and prednisolone. Betamethasone $(8 \mathrm{mg})$ and prednisolone $(40 \mathrm{mg})$ were administered daily for 10 days with a washout period of 10 days between. In this first part of the study betamethasone was administered intramuscularly and prednisolone orally. Placebo injections and tablets were used. Mean $\mathrm{FEV}_{1}$ was not significantly different before each period. There was a significant increase in $\mathrm{FEV}_{1}$ while they were taking betamethasone but not prednisolone. Individual analysis of the data showed that $\mathrm{FEV}_{1}$ increased with betamethasone in nine patients and remained stable or decreased in three. During treatment with prednisolone baseline FEV $_{1}$ increased moderately in three patients $\left(\mathrm{FEV}_{1} \mathbf{0 . 3}, 0.5\right.$ and $\left.0.6 \mathrm{l}\right)$ and remained stable or decreased in nine. There was no significant difference between the bronchodilator responses to cumulative doses of inhaled salbutamol when they were measured immediately before, on the last day of treatment with each steroid, and between steroid treatment periods. The same protocol was followed four months later in five of the 12 patients but both drugs were administered orally on this occasion. Similar results were obtained. The greater effect of betamethasone on bronchial obstruction may be due to its longer biological half life or to some unidentified property of its metabolites. The bronchial response to inhaled $\beta_{2}$ agonist appears not to be influenced by either steroid in these patients.

\section{Introduction}

Since the first observation by Carryer ${ }^{1}$ in 1952 of the dramatic effect of corticosteroid treatment in asthma, oral or injected corticosteroids have been prescribed extensively in the treatment of acute severe asthma, severe stable chronic asthma, and periods of worsening obstruction in asthmatic patients. ${ }^{2}$

Indeed, some authors ${ }^{3}$ consider the reversibility of bronchoconstriction on these drugs as a compulsory criterion for the diagnosis of asthma. It has, however, been the experience of chest physicians that some patients with chronic asthma ${ }^{4}$ are totally or partially resistant to treatment with systemic prednisolone even in very high doses. There is little doubt about the

Address for reprint requests: Dr B Grandordy, Cardiothoracic Research Institute, Brompton Hospital, London SW36HP.

Accepted 7 July 1986 diagnosis of asthma in these patients because clinical data usually fit the American Thoracic Society criteria $^{5}$ and the airway obstruction is considerably improved by inhalation of bronchodilator drugs. Although these patients are rare, they are responsible for a noticeable percentage of admissions to hospital for asthma, because the course of the disease is generally severe owing to resistance to oral steroid treatment and resistance to some other drugs, such as cromoglycate and xanthine derivatives. ${ }^{4}$

The major therapeutic benefits of corticosteroid treatment probably result from the suppression of inflammation and the facilitation of sympathetic nervous function. ${ }^{6}$ Knowing that betamethasone and prednisolone have different anti-inflammatory effects, ${ }^{7}$ we set out to determine whether betamethasone could alleviate airway obstruction in asthmatic patients showing partial resistance to prednisolone, and whether either corticosteroid could modify $\beta$-adrenergic function in these patients. 

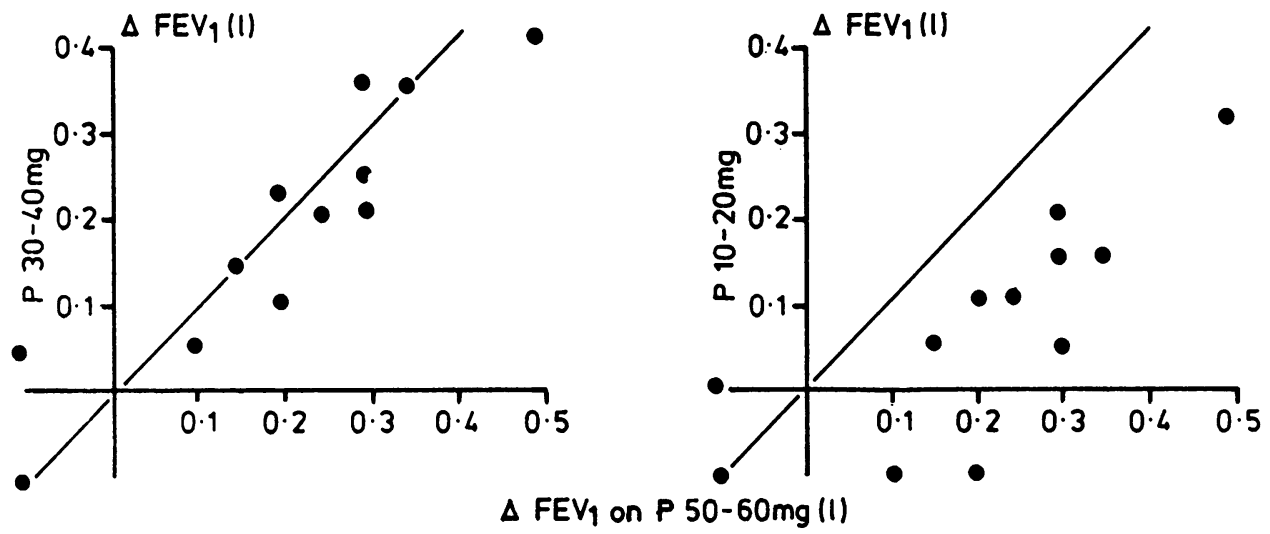

Fig 1 Relationship between increase in $F E V_{1}\left(\triangle F E V_{1}\right)$ after treatment with prednisolone $(P)$ for 10 days in a daily dose of $50-60 \mathrm{mg}$ (abscissa) and a daily dose of 30-40 mg (left) and a daily dose of 10-20 mg (right). The line is the line of identity.

\section{Methods}

\section{EXPERIMENTAL DESIGN}

We selected patients in whom $\mathrm{FEV}_{1}$ variation had never exceeded $20 \%$ of its predicted value during treatment with prednisolone in a dose ranging from 20 to $60 \mathrm{mg}$ daily for at least 10 days, whenever prednisolone had been prescribed for exacerbations of their disease in the three previous years. Twelve patients entered the study, for whom four to 10 such prescriptions had been made. The variations in best $\mathrm{FEV}_{1}$, noted while they were taking prednisolone daily for 10 days in a dose of $50-60 \mathrm{mg}$ and in a dose of $30-40 \mathrm{mg}$, were similar, but there was a difference in variation between the $50-60 \mathrm{mg}$ dose and the lower doses (fig 1). We therefore evaluated the effect of prednisolone (prednisolone metasulfobenzoate: Solupred (Houde-Ish), $\mathbf{4 0} \mathrm{mg}$ daily orally) versus the effect betamethasone in an equipotent antiinflammatory dose (betamethasone sodium phosphate: Betnesol (Glaxo), $8 \mathrm{mg}$ daily intramuscularly). The study was completed within four weeks for each of the 12 patients, we used a double blind randomised crossover design, the first drug received by each patient being determined with a randomisation number table. Each steroid was administered for 10 days every morning with a washout period of 10 days between the two periods. For reasons of convenience and local practice, prednisolone was given orally and betamethasone by intramuscular injections; placebo injections and tablets were used in both periods. Cumulative dose-response curves for inhaled salbutamol were constructed immediately before and on the last day of treatment with each steroid (five inhalations of $200 \mu \mathrm{g}$ at 15 minute intervals).

In the second part of the study five patients out of 12 (Nos $1,4,7,9,12)$, selected at random by the toss of a coin, followed a similar protocol but received the steroids in the reverse order from that used in the first trial; on this occasion both preparations were given $\vec{\theta}$ orally in the form of powder made from crushed tab- $\stackrel{\infty}{v}$ lets. This second part of the study was performed on average 19 (SD 2) weeks after the first part.

After the study patients were seen on two more occasions, at two week intervals, for assessment of their clinical state and measurement of 8 am cortisol $\stackrel{\circ}{\mathbb{Q}}$ blood concentrations.

To ensure compliance with the treatment, patients $\overline{\overrightarrow{0}}$ were asked to bring back their drug packages. All of the patients had volunteered for previous studies and were well trained. All patients gave their informed consent to the study.

EXPERIMENTAL DETAILS

Oral or injected corticosteroids had not been prescribed in the month preceding the study; no patients received inhaled steroids. Bronchodilator drugs were $\frac{3}{3}$ avoided for at least 12 hours before each bronchodilator test day but continued at an optimal dosage on the other days; sodium cromoglycate, when $\frac{7}{0}$ prescribed, was not discontinued. No patient was receiving anticonvulsants or macrolides. The four or cumulative dose-response curves were obtained at $9_{N}$ am in all patients. Salbutamol inhalations were care- 공 fully supervised and taken at the beginning of $a^{\omega}$ forced inspiration. Patients held their breath for four seconds. FEV 1 and forced vital capacity (FVC) were measured. Predicted values were those of the SEPCR. ${ }^{8}$ Peak expiratory flow (PEF) was monitored twice daily during the course of the study (7 am and 7$\mathrm{pm}$ ) before the administration of any drug.

STATISTICAL ANALYSIS

A two way analysis of variance (ANOVA) was used 
For paired observations the significance of differences between sample means was determined by Student's $t$ test. In this way each subject served as his or her own control. Interaction between order and treatment in this two period crossover trial was determined with the test described by Hills and Armitage. ${ }^{9}$

\section{PATIENTS}

Table 1 gives clinical data and initial and predicted $\mathrm{FEV}_{1}$ for all patients. The investigation was performed in 12 adult outpatients meeting the American Thoracic Society criteria for asthma. ${ }^{5}$ None of them were smokers. All suffered from severe perennial asthma with a chronic obstructive syndrome. All patients were known to be responsive to $\beta_{2}$-agonists: in the month preceding the study an $\mathrm{FEV}_{1}$ variation of more than $15 \%$ of the $\mathrm{FEV}_{1}$ predicted value, after $1 \mathrm{mg}$ of inhaled salbutamol, had been documented. All patients except patients 3,4 , and 11 considered themselves as stable on entering the study: treatment had not been changed in the last month, no recent worsening of exertional dyspnoea or nocturnal asthma had been noticed, and for one month there had been no consistent changes in PEF.

All patients were taking at least two bronchodilator drugs (long acting theophylline and/or $\beta_{2}$ agonist and/or anticholinergic) at optimal dosage on a long term basis. When acute exacerbations of dyspnoea occurred, all used additional inhalations of pressurised aerosols or nebulised solution of salbutamol delivered by an ultrasonic device. Daily physiotherapy was a requirement for respiratory comfort. None of the patients suffered from gastrointestinal or liver disease.

\section{Results}

According to the scheme of randomisation, patients 1-6 underwent betamethasone treatment before prednisolone and patients 7-12 took prednisolone first.

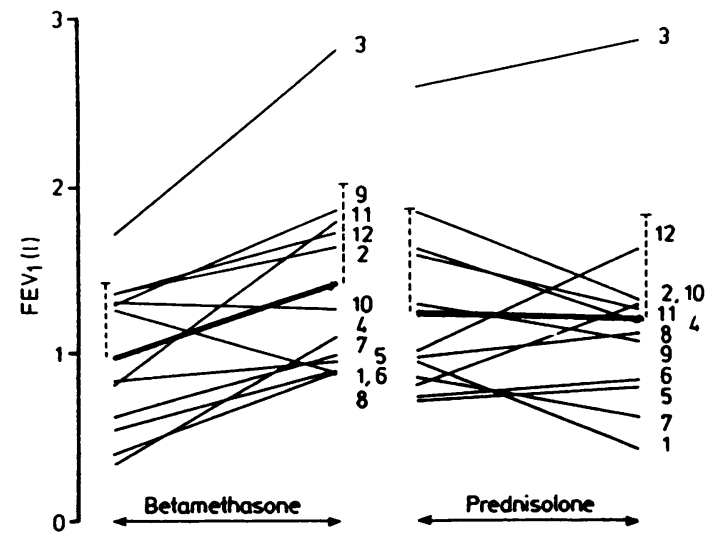

Fig $2 F E V_{1}$ before and after betamethasone $(8 \mathrm{mg}$ daily intramuscularly for 10 days) and prednisolone (40 mg daily orally for 10 days) in 12 asthmatic patients. The thick lines indicate mean values for the group.

There was no difference in the initial functional indices $\left(\mathrm{FEV}_{1}, \mathrm{FVC}, \mathrm{PEF}\right)$ between the two study periods. This study showed a significant effect of betamethasone but not of prednisolone on airway obstruction.

Figure 2 gives individual and mean $\mathrm{FEV}_{1}$ before and after each period of steroid treatment. There was no significant difference between the initial $\mathrm{FEV}_{1}$ of the two periods; the $\mathrm{FEV}_{1}$ variation was significant $(p<0.05)$ (difference between post-treatment $F V_{1}$ and initial value) was significant after betamethasone $(p<0.05)$ but not after prednisolone. The order of administration of the drugs in the two groups did not influence the bronchial response to the drugs. Mean $\mathrm{FEV}_{1}$ was significantly higher after betamethasone than after prednisolone ( $\mathrm{p}<0.05)$.

Figure 3 shows individual and mean $\mathrm{FEV}_{1}$ after inhalation of $1 \mathrm{mg}$ salbutamol before and after each treatment period. There was no significant difference in $\mathrm{FEV}_{1}$ after salbutamol inhalation between the two

Table 1 Clinical and functional characteristics of 12 patients with asthma

\begin{tabular}{|c|c|c|c|c|c|c|c|c|}
\hline $\begin{array}{l}\text { Patient } \\
\text { No }\end{array}$ & $\begin{array}{l}\text { Age (y) } \\
\text { and sex }\end{array}$ & Height (m) & $\begin{array}{l}\text { Asthma } \\
\text { duration (y) }\end{array}$ & $\begin{array}{l}\text { Current } \\
\text { treatment }\end{array}$ & Atopy & $\begin{array}{l}\text { FEV } \\
\operatorname{pred}^{1}(l)\end{array}$ & $F E V_{1} B$ & $F E V_{1} P$ \\
\hline $\begin{array}{r}1 \\
2 \\
3 \\
4 \\
5 \\
6 \\
7 \\
8 \\
9 \\
10 \\
11 \\
12\end{array}$ & $\begin{array}{l}55 \mathrm{M} \\
35 \mathrm{M} \\
31 \mathrm{M} \\
50 \mathrm{M} \\
25 \mathrm{~F} \\
40 \mathrm{~F} \\
50 \mathrm{M} \\
35 \mathrm{M} \\
36 \mathrm{M} \\
40 \mathrm{M} \\
40 \mathrm{~F} \\
24 \mathrm{~F}\end{array}$ & $\begin{array}{l}1.61 \\
1.71 \\
1.65 \\
1.71 \\
1.50 \\
1.45 \\
1.65 \\
1.59 \\
1.62 \\
1.68 \\
1.56 \\
1.75\end{array}$ & $\begin{array}{r}15 \\
7 \\
3 \\
26 \\
3 \\
8 \\
15 \\
4 \\
16 \\
25 \\
10 \\
2\end{array}$ & 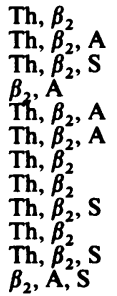 & $\begin{array}{l}- \\
+ \\
+ \\
+ \\
+ \\
- \\
- \\
+ \\
+ \\
+ \\
+\end{array}$ & $\begin{array}{l}2.52 \\
3.55 \\
3.40 \\
3.05 \\
2.28 \\
1.94 \\
2.75 \\
2.99 \\
3.35 \\
3.26 \\
2.23 \\
3.44\end{array}$ & $\begin{array}{l}0.39 \\
1.16 \\
1.69 \\
0.31 \\
0.84 \\
0.53 \\
0.63 \\
1.25 \\
1.25 \\
1.31 \\
0.78 \\
1.16\end{array}$ & $\begin{array}{l}0.98 \\
1.88 \\
2.63 \\
1.67 \\
0.72 \\
0.74 \\
0.86 \\
0.98 \\
1.31 \\
0.78 \\
1.61 \\
0.80\end{array}$ \\
\hline
\end{tabular}

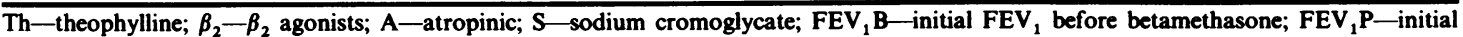
FEV 1 before prednisolone. 


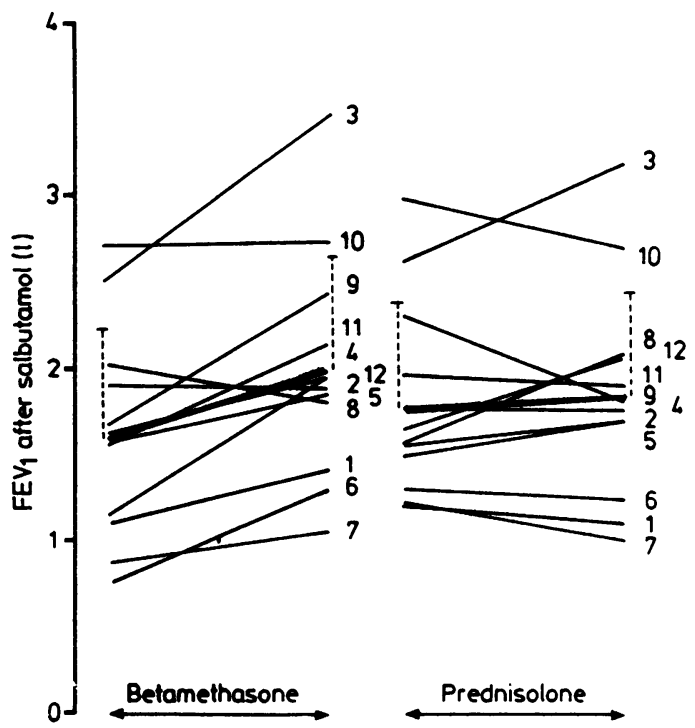

Fig 3 FEV $V_{1}$ after inhalation of $1 \mathrm{mg}$ salbutamol in 12 asthmatic patients before and after treatment with betamethasone and prednisolone. The thick lines indicate mean values for the group.

steroid treatment periods. $\mathrm{FEV}_{1}$ variation was significant after treatment with betamethasone $(p<$ 0.05 ) but not after treatment with prednisolone. $\mathrm{FEV}_{1}$ after inhalation of $1 \mathrm{mg}$ salbutamol was significantly higher after betamethasone than after $\Rightarrow$ prednisolone treatment $(p<0.05)$.

Figure 4 shows mean cumulative dose-response curves for salbutamol before and after each steroid, treatment period; the bronchodilator effect is expressed as increase in $\mathrm{FEV}_{1}$ above the baseline@ value. There was no significant difference between the four curves considered. FEV $_{1}$ variations were not $\rightarrow$ different on any of the study days for each of the five:cumulative doses of salbutamol by paired $t$ test. Indi- $\vec{\omega}$ vidual analysis of the data shows that for none of the? patients was the magnitude of $\mathrm{FEV}_{1}$ variation greater $\overrightarrow{\times}$ with betamethasone than with prednisolone.

Table 2 shows the mean PEF at 7 am and $7 \mathrm{pm}$ on the first, the fifth, and the last days of each steroido treatment period.

At the end of each treatment period patients were asked about improvement. Eight patients treated with

Table 2 Mean (SD) peak expiratory flow (PEF) expressed as percentage of predicted value at 7 am and $7 \mathrm{pm}$ on the first, the fifth, and the 10th day of each steroid treatment period

\begin{tabular}{|c|c|c|c|c|}
\hline & \multicolumn{2}{|c|}{ Betamethasone } & \multicolumn{2}{|c|}{ Prednisolone } \\
\hline & $7 \mathrm{am}$ & $7 p m$ & $7 a m$ & $7 p m$ \\
\hline $\begin{array}{l}\text { Day } 1 \\
\text { Day } 2 \\
\text { Day } 3\end{array}$ & $\begin{array}{l}31(10) \\
37(11)^{*} \\
45(12)^{*}\end{array}$ & $\begin{array}{l}42(13) \\
47(14)^{*} \\
49(15)^{*}\end{array}$ & $\begin{array}{l}32(11) \\
31(10) \\
33(12)\end{array}$ & $\begin{array}{l}43(13) \\
40(15) \\
42(12)\end{array}$ \\
\hline
\end{tabular}

*Paired $t$ test: significantly different from baseline values $(\mathrm{p}<0.05)$. PEF at 7 am was also significantly different on day 10 than on day 5 during treatment with betamethasone.
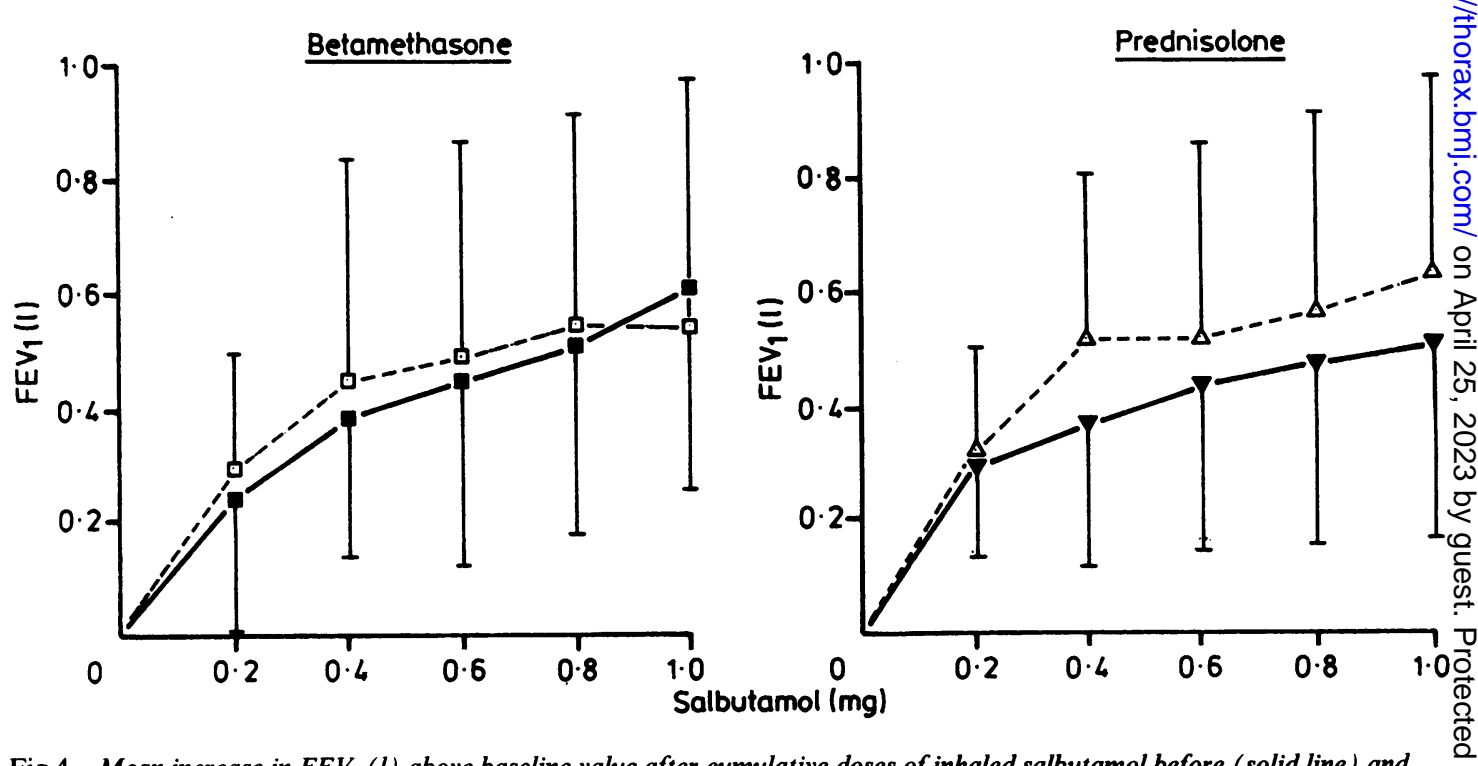

Fig 4 Mean increase in FEV (l) above baseline value after cumulative doses of inhaled salbutamol before (solid line) and after (interrupted line) betamethasone (left) and prednisolone (right) treatment. The bars indicate the standard error of mean. 


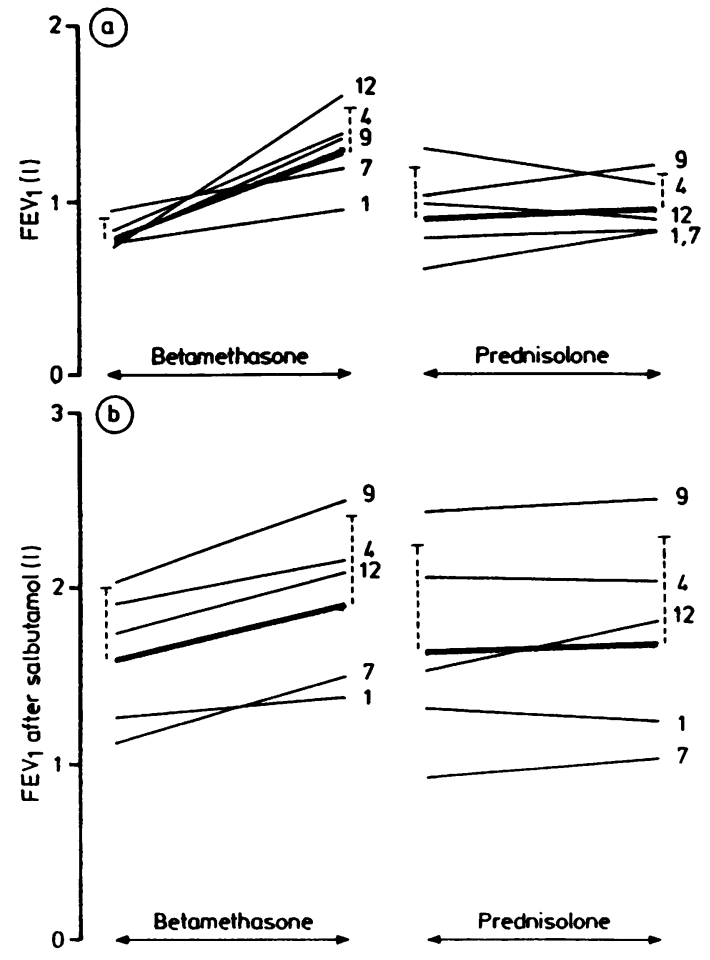

Fig $5 F E V_{1}$ and $F E V_{1}$ after inhalation of $1 \mathrm{mg}$ of salbutamol before and after treatment with oral betamethasone and oral prednisolone. Data are from five subjects who participated in the first study of intramuscular betamethasone and oral prednisolone. In the oral study the drugs were in each instance given in the reverse order. The thick lines indicate mean values for the group.

betamethasone and three treated with prednisolone claimed subjective improvement. None of them reported deterioration at the time of the last poststudy visit. Blood pressure remained unchanged in all patients at all visits. Two patients reported a weight gain of less than $2 \mathrm{~kg}$ by the end of the study. No patient complained of muscle pain but three complained of epigastric pain with both betamethasone and prednisolone. The plasma concentration of cortisol was diminished by more than $25 \%$ in five patients at the first post-study visit but had returned to normal by the last visit.

The results of the second part of the study were similar to those of the first part. FEV $_{1}$ increased significantly with betamethasone but not with prednisolone (fig $5 a$ ). Mean FEV ${ }_{1}$ after inhalation of $1 \mathrm{mg}$ salbutamol was not significantly different before the two steroid periods; mean $\mathrm{FEV}_{1}$ after inhalation of salbutamol was greater after betamethasone treatment than it was before treatment $(p<0.05)$ but showed no significant difference after treatment with prednisolone (fig $5 b$ ).

\section{Discussion}

Prednisolone resistant asthma has been reported recently by Carmichael et al. ${ }^{410}$ As in these studies, the course of the disease in our patients was severe, but no striking clinical features allowed discrimination from prednisolone sensitive patients. Resistance to steroids other than prednisolone has not been reported, but this may be due to more restricted use of these drugs.

Resistance to prednisolone is probably never complete and according to published criteria ${ }^{4}$ we selected patients known to have poor reversibility of airway obstruction with a high dose regimen of prednisolone. In these patients treatment with betamethasone resulted in a significant increase in $\mathrm{FEV}_{1}$, but treatment with prednisolone in equipotent antiinflammatory doses did not. Individual analysis of the data shows that during treatment with betamethasone $\mathrm{FEV}_{1}$ increased in all patients except one (No 8). Betamethasone behaves as if it is a more potent steroid than prednisolone, although it may fail in some patients (No 8), which may be due perhaps to inadequate dosage or duration of treatment. In no patient did treatment with betamethasone succeed in completely alleviating airway obstruction, and mean FEV $_{1}$ improvement after betamethasone in the 12 patients was less than $450 \mathrm{ml}$ (fig 2).

Individual analysis of the data of the three patients $(3,4,11)$ who claimed to be in an unstable respiratory condition at the time of the study suggests that their better response to betamethasone might be due to poorer $\mathrm{FEV}_{1}$ before betamethasone than before prednisolone treatment. But the observed $\mathrm{FEV}_{1}$ variation with betamethasone $(1.2,0.78$, and 1.041 respectively in the first part of the study and 0.581 for patient 4 in the second part of the study) was higher than the variation previously observed during prednisolone treatment in the same patients, when they were seen with even lower $\mathrm{FEV}_{1}$. Furthermore, there is striking evidence that $\mathrm{FEV}_{1}$ may deteriorate during prednisolone treatment (patients 4 and 11), or that airway obstruction may not be completely alleviated by this drug whenever improvement is achieved by $\beta$ agonists (patient 3), thus confirming the relative lack of efficacy of prednisolone in these patients.

The time course of the development of prednisolone resistance over months or years is not known. In our study five patients $(1,4,7,9,12)$ showed an unchanged pattern of response to prednisolone and betamethasone after a mean period of four months as demonstrated in the second study, even though both drugs were administered in the reverse order from that of the first study.

Causes of resistance to prednisolone in man are not known. Development of resistance to glucocorticoid 
Grandordy, Belmatoug, Morelle, De Lauture, Marsac

hormones has been attributed to synthesis of new proteins in animals ${ }^{11}$ but it is not known whether steroid resistance is inherited or acquired in man.

Impairment of normal steroid pharmacokinetics in man could produce prednisolone resistance. The route of administration, however, has no clinical relevance to prednisolone metabolism, ${ }^{1213}$ and the systemic bioavailability of tablets is similar to that of intravenous aqueous-alcoholic solution. There is an equivalent absorption into the systemic circulation after administration of a given dose by the two routes. ${ }^{14}$ Furthermore, the pharmacokinetic behaviour of prednisolone has been reported to be normal in asthmatic subjects. ${ }^{15}$ Although we did not measure pharmacokinetic indices in our patients, there is no reason to suspect any defect in absorption or metabolism of prednisolone as no patients suffered from gut or liver disease. Furthermore, the pharmacokinetic behaviour of betamethasone is not affected by the route of administration, ${ }^{16-19}$ provided that gastrointestinal function and liver function are both normal. The fact that both the oral and the intramuscular administration of the same dose of betamethasone elicited an alleviation of airway obstruction in our patients after an interval of four months gives further support to the contention that the route of administration has no relevance to the effect of the drug. A deficiency of receptors could not explain prednisolone resistance since in our patients steroid receptors were stimulated by betamethasone and since there is some evidence of normal steroid receptors in asthmatic patients. ${ }^{20}$

Part of the action of corticosteroids on asthmatic bronchi may depend on inhibition of inflammatory response to immunological and non-immunological stimuli. $^{2}$ We therefore matched dosages of betamethasone and prednisolone according to their reported anti-inflammatory properties. Antiinflammatory potency of various pure steroids has been estimated with different bioassays evaluating early and last phases of non-specific inflammation, but such relative potencies are not fixed ratios and vary considerably with the conditions of the bioassay used. $^{7}$ Several different bioassays have been used, such as kaolin injection in rat pad, rat myocardial infarction, ${ }^{21}$ and inhibition of hyaluronidase secretion. ${ }^{22}$ This may explain why equipotency between betamethasone and prednisolone has been reported at dose ratios of $1: 4^{6}$ to $1: 8 .^{7}$ Although it may be argued that the dose ratio that we used in our study (1:5) might bias the results in favour of betamethasone, the similar FEV $_{1}$ improvement obtained previously with either $30-40 \mathrm{mg}$ or $50-60 \mathrm{mg}$ of prednisolone (fig 1 ; offers indirect evidence that in our patients the dose of prednisolone was of little importance and that the drug itself was generally inefficient.

The difficulty of evaluating equipotent anti ther complicated by the fact that the steroids available in clinical practice are steroid esters, whose anti-inflammatory effect may be different from that o $\overline{\bar{B}}$ pure steroids. Among prednisolone esters, only the anti-inflammatory potency of prednisolone steaglate has been evaluated to our knowledge, and it does not seem to be related to the molecular weight of the salt. $^{23}$

Although the doses we used are in the range of reported equipotent doses for betamethasone and prednisolone, their bronchial effects on the com ponents of airway inflammation were different. The better bronchial effect of betamethasone than predis nisolone may be due to the longer biological half lifer of betamethasone ( 36 versus 8 hours). Steroid dosage and timing of the doses have some relevance in chronic asthma.

Another possible hypothesis is that the cellula metabolism of betamethasone might differ from tha of prednisolone or that one of betamethasone's metabolites might exert a potent anti-inflammatoryo effect. Neither hypothesis has been investigated to our knowledge.

The increase in $\mathrm{FEV}_{1}$ after inhalation of sals butamol was quite large in our patients. Even aftep betamethasone, however, the response to salbutamos was not modified. This is in contrast to usual experia ence in severe asthma, in which steroids are adminis $\vec{\not}$ tered to facilitate sympathetic nervous function, ${ }^{6}$ and $B$ it contrasts with in vitro observations that cortico? steroids enhance secretion of cyclic AMP after $\bar{\beta}$. receptor stimulation. ${ }^{24}$ Pathological investigations in acute severe asthma, however, show diffuse mucu? plugging of bronchioles, ${ }^{25}$ which may inhibit pene tration of inhaled bronchodilators. Our patients did not display the acute dyspnoea syndrome or acute severe asthma, but had severe chronic obstructiono Bronchial changes may therefore have been differen from those of acute severe asthma and airway perme음 ability may have been at least partially preserved. $D$

The increase of $\mathrm{FEV}_{1}$ after inhalation of sal․ㅡㄹ. butamol cannot be attributed to a ceiling effect of bronchodilatation since none of our patients reached $100 \%$ of the predicted $\mathrm{FEV}_{1}$ with steroid treatment alone. After inhaling salbutamol two patients (3 and 10) reached $94 \%$ and $83 \%$ of the predicted FEV Although these patients were good responders to salo butamol, which justified the long term prescription of bronchodilators that we started in these patietns, the $e^{+}$ severity of their disease was more related to the rapido recurrence of bronchial obstruction when the effect of the $\beta_{2}$ agonist had vanished after a few hours, an this could have been a consequence of the sever\& inflammatory course of their disease. 
We have already started high dosage inhalation steroid in these patients and our experience suggests that dexamethasone and beclomethasone, whose chemical structure is very close to that of betamethasone, may improve respiratory function in at least some of them.

We thank Pr Alain Lockhart for helpful assistance and V Gazier and E Robinson for their typing skills.

\section{References}

1 Carryer JM, Koelshe GA, Prickman LE, Maytum CK, Lake CF, Williams HL. Effects of cortisone on bronchial asthma and hayfever occuring in subjects sensitive to ragweed pollen. J Allergy 1950;21:282-7.

2 Cochrane GM. Systemic steroids in asthma. In: Clark TJH, ed. Steroids in asthma. London: Adis Press, 1983:103-20.

3 Fournier M, Pariente R. La place des corticoides dans la therapeutique actuelle de l'asthme. Assises de medecine: l'asthme. Paris: Expansion Scientifique, 1978:34-9.

4 Carmichael J, Paterson IC, Diaz P, Crompton GK, Kay AB, Grant IWB. Corticosteroid resistance in chronic asthma. Br Med J 1981;282:1419-22.

5 American Thoracic Society Committee on Diagnosis Standards for Non-Tuberculous Disease. Definitions and classification of chronic bronchitis, asthma, and pulmonary emphysema. Am Rev Respir Dis 1962; 85:762-9.

6 Gebbie T. Therapeutic choices in asthma. In: Clark TJH, ed. Steroids in asthma. London: Adis Press, 1983: 83-102.

7 Haynes RC jun, Murad F. Adreno-cortical steroids and their synthetic analogs. In: The pharmacological basis of therapeutics, eds. Goodman L, Gilman A. New York, Macmillan 1980:1470-92.

8 Quanjer PH, ed. Standardized lung function testing. Bull Eur Physiopath Respir 1983;19 (suppl 5):7-10.

9 Hills M, Armitage $P$. The two-period cross-over clinical trial. Br J Clin Pharmacol 1979;8:7-20.

10 Kay AB, Diaz P, Carmichael J, Grant IWB. Corticosteroid-resistant chronic asthma and monocyte complement-receptors. Clin Exp Immunol 1981; 44:576-80.

11 Voris BP, Nicholson ML, Young DA. Development of resistance to glucocorticoid hormones during rat thymus cell differentiation: proteins associated with emergence of the resistant state. Cancer Res 1983;43:1236-43.

12 Bergram H, Grottum P, Rugstad HE. Pharmacokinetics and protein binding of prednisolone after oral and intravenous administration. Eur J Clin Pharmacol 1983;24:415-9.

13 Pickup ME. Clinical pharmacokinetics of prednisone and prednisolone. Clin Pharmacol 1978;4:111-28.

14 Antal EJ, Wright CE, Gillepsie WR, Albert KS. Influence of route of administration on the pharmacokinetics of prednisolone. J Pharmacol Biopharmacol 1983;11:561-76.

15 McAllister WAC, Winfield CR, Collins JV. Pharmacokinetics of prednisolone in normal and asthmatic subjects in relation to dose. Eur J Clin Pharmacol 1981;20:141-5.

16 Petersen MC, Nation RL, McBride WG, Ashley JJ, Moore RG. Pharmacokinetics of betamethasone in healthy adults after intravenous administration. Eur $J$ Clin Pharmacol 1983;25:643-50.

17 Petersen MC, Collier CB, Ashley JJ, McBride WG, Nation RL. Disposition of betamethasone in parturient women after intravenous administration. Eur J Clin Pharmacol 1983;25:803-10.

18 Murphy D, West HF, Bethel AM. Some aspects of the metabolism and disposition of betamethasone. Acta Endocrinol 1964;45:498-508.

19 Tsuei SE, Moore RG, Ashley JJ, McBride WG. Disposition of synthetic glucocorticoids. I. Pharmacokinetics of dexamethasone in healthy subjects. $J$ Pharmacokinet Biopharmacol 1979;7:249-64.

20 Tsai BS, Watt G, Koes Nadi K, Townley G. Lymphocyte glucocorticoid receptors in asthmatic and control subjects. Clin Allergy 1984;14:363-71.

21 Fauci AS. (moderator, National Institutes of Health Conference). Glucocorticosteroid therapy: mechanisms of action and clinical considerations. Ann Intern Med 1976;84:304-15.

22 Saarni H, Hopsy-Havu VK. The decrease of hyaluronate synthesis by anti-inflammatory steroids in vitro. $\mathrm{Br} J$ Dermatol 1978;98:445-9.

23 Anonymous. Corticosteroids. In: Wade A, ed. Martindale: the extra pharmacopeia. London: Pharmaceutical Press, 1982:446-53.

24 Rinard GA, Jensen A, Puckett AM. Hydrocortisone and isoproterenol effects on trachealis AMPc and relaxation. J Appl Physiol 1983;55:1609-13.

25 Dunnill MS. The morphology of the airways in bronchial asthma. In: Stein M, ed. New directions in asthma. Park Ridge: American College of Chest Physicians 1975:213-21. 